\title{
Exploring the Potential of online English Websites In Teaching English To Non-Linguistic Major Students: BreakingNewsEnglish As Example
}

\author{
Viktoriia S. Abramova \\ Perm State University \\ abramovavictoria@yandex.ru
}

Saad Boulahnane

Hassan II University

saad.boulahnane@fulbrightmail.org

DOI: http://dx.doi.org/10.18326/rgt.v12i1.1-12

\begin{abstract}
Submission
ABSTRACT

Track:

Received:

$22 / 04 / 2019$

The Internet has captured the attention of teachers and language instructors from all over the world due to its online teaching materials.

Final Revision: The Internet-based material has allowed distance-learning projects.

$15 / 05 / 2019$ This article explores the potential role of EFL websites as a supplement in classroom instruction. As an example, an English-

$15 / 05 / 2019$

Available online: language based news website, www.breakingnewsenglish.com, has

$01 / 06 / 2019$ been designed to teach English to non-linguistic major students. The authors of this article offer methodological recommendations on using Internet-based materials, describe stages of work with authentic texts,

Corresponding and note linguistic and communicative skills developed in the course of work. The recommendations have been formed based on teachers and

Author: students' descriptions of the materials provided by the website in question. This descriptive article will hopefully contribute to the

Saad Boulahnane literature on online teaching and learning materials, particularly in
\end{abstract} saad.boulahnane

@fulbrightmail.org

Keywords: foreign languages, online educational resource, news website, communicative skills 


\section{INTRODUCTION}

Of all the services the Internet has made available over the last two decades, websites providing access to new methods of communication, research, and education represent a substantial share of the market. The Internet has become of significant importance in the context of distance and self-learning, which has been enabled and enhanced via many educational applications (Baron \& Bruillard, 1996). This significance has therefore become a locus of interest for universities from all over the world, which are now involved in distance learning projects supported by websites. The mélange of computers and websites with well-evaluated pedagogical materials has resulted in substantial education-related potential (Kartal \& Uzun, 2010).

Language learning websites have the potential to develop both learners' proficiency and other skills closely connected with language. It is therefore noted that websites on foreign language teaching and learning are considered unavoidable elements of CALL, which stands for Computer Assisted Language Learning. The Internet's substantial contribution and potential must then be utilized more efficiently (Kartal \& Uzun, 2010).

Barnes (2009) believes that social networks and virtual worlds are now inextricably linked with people's everyday life, which correlates with the constant curiosity of how people interact with each other. More specifically, Parks (2009) points out the rapid growth of Internet-based applications and computer games in the last fifteen years and how this increased interest has led to research on communication in this realm

Further studies on web-based learning regard the field as clearly beneficial for both educators and learners alike. Mkrtchian et al. (2019) examined the development of distance learning and digitization of training with a particular focus on the stages of development and processes leading to new quality methodologies in education. The study focused on effective factors for achieving high levels of development, depending on certain university criteria. The study investigated whether a media-based reading program would have a significant contribution to students' reading comprehension. It adopted a web-based reading training program designed and implemented to measure EFL University students' reading skills. In the quasi-experimental study, the experimental group scored significantly higher than the control group. The students also provided positive and encouraging feedback on the use of the web-based program (Chang \& Lin, 2019). Another study investigating the role of English teaching websites showed English language learners resorted to the Internet for help regarding their learning, general information, and games. These factors would therefore constitute the prevailing characteristics of an ideal English language learning website (Kir \& Kayak, 2013) 
In spite of existing abundantly on the Internet, foreign language teaching websites need to be investigated based on their organization, pedagogy, and methodology, according to Lancien (1998a), who maintains that there is still a paucity in standardized unity and management in most language teaching websites. In the same vein, Mangenot (1998a) adds that these foreign language teaching sites are diverse at the structural and the contextual levels, leading to them deviating from their preliminary aim.

The majority of language learning websites do not utilize the full potential of the Internet, with the pedagogical approach reduced to certain basic reading skills. Learning sites, according to Kartal (2005), still need to reflect pedagogical scenarios and learning theories, which are absent on most websites, including the learning objectives, proficiency levels, and the target audience. Despite what has been said, researchers recognize several pedagogical benefits offered by the Internet regarding foreign language learning, suggesting that online authentic materials, provided in any format, boost the learning and teaching processes (Lancien, 1998a; Mangenot, 1998b). The Internet, therefore, remains supplemental to education and provides learners and teachers with an easily accessible environment with diverse practice materials.

From the didactic point of view, Internet-based technologies for teaching a foreign language optimize mental load of students, stir up their cognitive activity, direct and control both processes - formation and development of speech skills and abilities when mastering foreign language activity. They also develop activeness and independence when addressing communicative and problem tasks. (Starodubtseva, 2017, p. 2)

Educational news websites, with their materials, are especially effective in creating linguistically diverse options in foreign language classes and are successful in illustrating components of the foreign language competence-namely, the grammatical, the lexical, the sociocultural, the compensatory, the educational, and the informative.

\section{RESEARCH METHOD}

The data described in this article consist of both the authors' observations and data resulting from semi-structured interviews with teachers and students using the website in question. The respondents were asked a variety of questions regarding their views on the potential that the website offers. Although the interviews were analyzed to elicit information 
about how the respondents use the website, and hence attempt to achieve generalizability, the authors of this article offered their own observations and methodological steps and recommendations to usher the reader into the ideal use of the English language teaching website potential. The data were collected through a convenience sample, which consisted of 35 teachers and students using the online English teaching website. A total of 26 students and 9 teachers were interviewed to elicit data regarding the teaching and learning features of the website.

\section{RESULTS \& DISCUSSION}

This article describes the potential of the educational news website www.breakingnewsenglish.com in teaching English as a foreign language to university students of non-linguistic majors. This news website provides worldwide breaking news in English and reports about new experiments and discoveries in a wide range of disciplinary backgrounds, including - but not limited to-chemistry, biology, physics, mathematics, economics, astronomy, social sciences, religion, philosophy, art, medicine, and many others. The website presents more than 2000 lessons based on current news - a number that is constantly increasing. Selecting one news story for a lesson over another depends on the proficiency ranking of the story, which is expressed on a scale of 0-6 scale, with 0 representing what the website considers suitable for rudimentary reading skills, and with 6 representing an independent reading level. Along with the website offering news article lessons tailored to the seven levels, it gives its learners the opportunity to make use of a variety of twenty-page long tasks. On the other hand, for those interested in a two-hour lesson, a two-page mini-lesson suffices. Each news lesson is followed by an audio recording, playable under different speech rates, including slow, an average native speaking pace, and a faster native speaking pace, in both British and American English pronunciation styles in addition to pronunciation exercises. Additionally, the news articles are accompanied by references and resources for further reading activities. This news website can be efficiently utilized to solve students' educational problems.

This article offers stages of work with the use of the news material taken from the website. It also notes linguistic and communicative skills developed in the course of work. The news materials are used in classes on the subject "General English" with university students of non-linguistic majors, namely: majors of philology, philosophy, general 
psychology, clinical psychology, sociology, culturology, and majors in youth activism. The news lessons are addressed to students with a minimum of pre-intermediate language proficiency-expressed as A2 level according to the Common European Framework Reference. Using www.breakingnewsenglish.com as a resource is expedient, particularly as a concluding session on a topic that would allow the learners to generally improve their English language and specifically enrich their lexicon by learning both general and situational vocabulary in context. The choice of the news lesson is connected not only to the topic studied e.g., Healthy Lifestyle, Shopping, Leisure Activities, Family Values, Locations and Directions, Cultural Attractions, Internet Communications, Learning and Memory, Water Resources, etc., but also to the presence of specific vocabulary and grammar related to the topic.

The ideas and exercises presented on the website are grouped on the basis of class activities. They are adapted and presented to students according to the teaching style and the classroom atmosphere. The following paragraphs will present the authors' recommended use of the website.

Working on an article lasts one university unit, which translates to 90 minutes. At the beginning of the class, 2-page mini-lesson handouts are given to the students, who are asked to think of keywords associated with the article heading. For example, working on the article entitled "Who Says Cut Music to an Hour a Day?", students express what springs to their mind when they hear the word 'music.' The heading is written on the board, and both the teacher and the students discuss it together. The students make assumptions about what the news article could be about and ask questions that they think are relevant and pertinent to the text. These exercises contribute to the building of an atmosphere of trust in the classroom, provide a further perspective on how the news can be read, and actively recycle the learned vocabulary on the topic.

The next step is studying the article's vocabulary. In this news resource, authentic vocabulary and collocations are used. It is advisable to write down new words, phrases and expressions, reductions, and idioms on the board with synonyms pertaining to the students' level opposite each expression. In this context, one of the students interviewed said:

I find the website material very useful. The reading passages are varied. They enriched my vocabulary. Also, the phrase match and the new words and synonyms and meanings 
[...] they have helped me to widen my vocabulary use. The reading passages have also helped me to improve my writing skills.

Learning new vocabulary from the website can take several forms. The teacher can ask the students to recycle sentences, thereby consolidating the newly acquired words. ${ }^{1}$ Vocabulary can also be acquired through the learning of synonyms, sentences, and phrase match. For instance, the phrase match exercise is a substantial way of learning ready-made chunks of language. Banville (2015) suggests:

Take phrases or word pairs from the text and split them. Students have to match the beginnings with their endings. Alternate between keeping collocation pairs or phrasal verbs intact and splitting them on either side of the match. There may be cognitive value in the surprise students experience in seeing the two parts of a phrasal verb or strong collocate being matched. Decisions need to be made regarding where best to make the split for the match. (p. 46)

Not only does the phrase match exercise help remind the students of what follows an expression from the text, it also helps strengthen language collocations or any linguistically common string of words. For example, after the first or second reading of a passage, the students should know what certain words are followed by, depending on the grammar structure - e.g. the expression 'in accordance' is followed by 'with' and not by a verb, a noun, or another part of speech. Phrase match helps ingrain these linguistically glued chunks. The students can learn this structure from the text and from memory as being words pre-organized in a certain way.

The phrase match exercise can also be designed by the students using three columns rather than two. The exercise is more fun because it mixes both matching and constructing sentences. Banville (2005) elucidates:

Create a phrase match with three columns. Students must match from left to middle to right in order to complete the match. [...] the words in the first and third columns are correctly placed. The words in the middle column are in the wrong order. (p. 3)

Another teacher respondent explained:

Learning synonyms is necessary to grow your English vocabulary. They also make it easy to understand native speakers, since they will use a lot of associated words in their 
speech. Phrase and synonym match are great exercises that provide students with a fun, engaging way to learn. Such activities help students improve their vocabulary and spelling abilities. They give an opportunity to learn object/word definitions as well as challenge learners logically. By using such techniques as inversion, diversion, and the process of elimination, learners are able to greatly increase the probability of answering questions correctly.

Following the vocabulary stage comes article scanning. As noted by Kirsanova (2001), "reading is an independent type of speech activity which provides a written form of communication" (p.85). Students are assigned the task of looking through the text before they answer the comprehension questions. They state which of the provided statements correspond to the text content (True) and which do not correspond to the text content (False). If the statement is incorrect, then it is necessary to explain why and correct the statement. Asking the students about the main idea of the article can also elicit interesting results, particularly if the questions are intentionally skewed towards the students' experiences. It is recommended that students be asked how the lesson theme relates to their life, which allows them more opportunity for expression. If the teacher notices that the students are at loss or have difficulties trying to understand certain parts of the text, he/she asks them to find keywords, outline the main idea, or translate the part of the text causing difficulty. In strong groups, a full translation of the article may be unnecessary. In low-level groups, on the other hand, translating the content of the studied text and working on the main grammatical structures can lead to appreciable results. Students can be offered additional tasks; e.g. finding synonyms for certain words from the text or giving definitions to the words in English. This would serve as valuable practice. Such exercises involve students both quantitatively and qualitatively; the activities correlate positively with the students' sense of independence and creativity.

Subsequently, both strong and weak students are asked to retell, in pairs, the content of the text in English. One student retells the first paragraph - the other, the second. This exercise helps assimilate the meanings of the new words in their context and acquire lexical and grammatical structures. During this phase - the oral reproduction of the text-students listen to each other carefully, correct each other's mistakes, and also ask questions related to the general understanding of the text. 
A new stage of work is listening to an audio recording based on the news article. Audio tracks of educational exercises and tasks provide simultaneous support on acoustical, visual, and motor memory (Starodubtseva, 2017). Students usually listen to recordings in British English, which is often played on average speed. They also have a printed version of the audio script in front of them. The first listening exercise helps form the complete image of the sounding text, which also improves their English pronunciation, namely: sounds, rhythm, intonation, and other sound-related peculiarities and skills. After the first listening exercise, the teacher focuses the attention on the students' pronunciation of certain words. During the second listening exercise, students orally reproduce the audio text consecutively after the speaker. The verbal production gives students the chance to automate a skill of adequate reproduction of the original text in the foreign language and also helps fulfill a natural rhythm and speed of pronunciation. As another option, instead of the students familiarizing themselves with the printed version of the text and the subsequent listening of an audio recording, the teacher can distribute the studied text, with gaps for the students to fill with words and expressions heard during the listening exercise. This step is done within the stage of the consecutive reproduction of the audio text. The aforementioned tasks are executed in a way that allows the students to address and work on authentic texts. By the end of the class, students should be able to give a short review of what the article is about and talk about its main idea.

The transition from the text to the practice of speaking skills is done through a class discussion, which is based on communication between two students. Communication-based situations are helpful in creating analogs in the classroom, leading to the students assimilating the use of certain language functions (Starodubtseva, 2017). In this context, the website offers synonym match and blank-filling exercises that corroborate the students' use of language units in certain contexts, rather than merely uttering words or expressions translated from the students' source language.

Two-page handouts always contain two sets of questions (Discussion - Student A, Discussion - Student B) intended for work in pairs. Each question relates to the studied problem. This type of work is of special interest as it motivates communication in a foreign language, allows students to form their own point of view on various current problems, promotes the development of cognitive activities, and helps show intellectual and creative activity and individuality. During the activity, the teacher approaches each pair of students 
and helps them. He/she monitors how well they practice new vocabulary and corrects their speaking mistakes and errors. The teacher can also help the students ask each other additional questions and discuss how the issue in question is approached in their own culture. On the importance of speaking, Malihah (2010) emphasizes that "speaking is a crucial part of second language learning and teaching" and that it is "not merely to let students repeat or memorize dialogues, but they should be able to use the utterance to communicate in real situations" (p. 85).

The following stage is working in mini-groups for participation in a role-play game (Role Play). In teaching, role-play method is of key importance. Shanlar et al (2012) note:

Role plays enable students to place themselves in the situation of another person and may help to develop empathy. Role plays early in the course can expose students to different situations they are likely to face in their future career. (p. 3)

The importance of role play lies in preparing the students, who are shy at times, to speak as an imaginary person, which spares them from opening up about their own opinions and views that they might be reluctant to speak about. The purpose of role-play in teaching is to allow students to create an imaginary situation and communicate according to what is expected both verbally and socially. This grants them more freedom to voice their opinions and express arguments since they are not constrained by the social rules and ethics existing in their society. For example, students who do not engage in shopping for alcohol-irrespective of the reasons behind their choice — can imagine a different context, which allows them to practice freely since the objective is speaking and communication. Practicing this method can take different forms. For instance, Listyani \& Kristie (2018) note:

The first strategy was role-play, in which students played a kind of roles and practiced a dialogue with their pairs. This activity can encourage students to speak and increase their vocabulary. (p. 150)

The authors of this article provide a slightly different method, in which the students are divided into groups, and each participant enacts one of the roles listed in the handouts. The group members make statements and act in accordance with the given role. For example, 
discussing an article under the heading "Study Shows Money Makes us Worry", four groups enact the following four roles: "money expert", "shopaholic", "big spender", and "exadvertiser." Correctly chosen and properly distributed, the roles motivate students to collaborate and interact with each other, program their speech behavior, and create a necessary communicative framework for developing social and speaking skills. For example, the "shopaholics" will have to prepare, within 10 minutes, a talk of 7-10 sentences in length on why they buy everything they see. They also speak of three reasons for their addictive shopping behavior. The performance of each group should last around five minutes. It is also important to prepare strong arguments that would convince other groups. The exercise is very effective and enables the development of communicative and speech skills. In addition to that, it develops the students' imagination and acting skills.

As homework, students are usually asked to make a speech using new words and expressions from the article. For example, after work on the article "Study Shows Money Makes us Worry", students prepare, under the theme of 'Shopping,' an oral presentation about a gift that they got for one of their family members, with a detailed description of the purchasing process.

\section{CONCLUSION}

In conclusion, practice with educational news website materials helps EFL teachers in many ways. They improve all types of linguistic activities and learning skills-i.e., reading, writing, listening, and speaking. They also develop students' communicative and cognitive abilities - e.g. accessing information, generalizing it, classifying it, analyzing the obtained information, representing it, and discussing it. Educational websites stimulate students' speaking activity and help them solve communicative and informative problems (Starodubtseva, 2017). Moreover, they can increase the students' motivation to learn English through these educational news articles. A further reason would be that they make students curious to learn more about current world issues and push them to read more in English. Finally, these websites prepare students for studying other subjects, such as English for specific purposes (ESP).

This article has provided some useful methodological steps for teachers with little experience in online teaching materials. Since online educational materials have been around 
only recently compared to other traditional materials, the steps offered above can benefit many teachers interested in Internet teaching materials.

\section{REFERENCES}

Banville, S. (2012). www.BreakingNewsEnglish.com 1000 Ideas and Activities for Language Teachers.

Barnes, S. B. (2009). Relationship networking: Society and education. Journal of ComputerMediated Communication, 14(3), 735-742.

Baron, G.L., \& Bruillard, E. (1996). L'Informatique et ses Usages dans l'Education. Paris: PUF.

Callahan, E. (2006). Cultural similarities and differences in the design of university web sites. Journal of Computer-Mediated Communication, 11(1), 239-273

Chang, M.-M., \& Lin, M.-C. (January 01, 2019). Experimental Study on Strategy-Oriented Web-Based English Instruction for EFL Students. Journal of Educational Computing Research, 56, 8, 1238-1257.

Kartal, E. (2005). The Internet and Autonomous Language Learning: A Typology of Suggested Aids. Place of publication not identified: Distributed by ERIC Clearinghouse.

Kartal, E. \& Uzun, L. (2010). The Internet, Language Learning, and International Dialogue: Constructing Online Foreign Language Learning Websites. Turkish Online Journal of Distance Education-TOJDE April, Vol.11, Number 2, pg. 90-104

Kirsanova O.F. (2001). Ispol'zovanie autentichnyh materialov na urokah anglijskogo yazyka kak sredstva formirovaniya inoyazychnoj kul'turologicheskoj kompetencii/URL: https://xn--i1abbnckbmc19fb.xn-p1ai/\%D1\%81\%D1\%82\%D0\%B0\%D1\%82\%D1\%8C\%D0\%B8/509250/

Kir, E., \& Kayak, S. (December 10, 2013). The Evaluation of Websites Teaching English as a Foreign Language (efl). Procedia - Social and Behavioral Sciences, 106, 2788-2795.

Lancien, T. (1998a). Réseau et Français Langue Etrangère. Conférence Virtuelle sur les Applications des TIC dans l'Enseignement du Français Langue Etrangère. Agence Intergouvernementale de la Francophonie, du 7 au 18 Décembre 1998. http://ciffad.francophonie.org/CONFFLE/RESSOURCES/contrib-lancien.html

Listyani, L. ., \& Kristie, L. S. (November 29, 2018). Teachers' Strategies to Improve Students' SelfConfidence in Speaking: A Study at Two Vocational Schools in Central Borneo. Register Journal, 11, 2, 139. 
Malihah, N. (June 01, 2010). The Effectiveness of Speaking Instruction through Task-Based Language Teaching. Register Journal, 3, 1, 85.

Mangenot, F. (1998). Classification des apports d'Internet à l'apprentissage des langues Classification of the Internet Contribution to Language Learning. Adalsic.

Mkrttchian, V., Krevskiy, I., Bershadsky, A., Glotova, T., Gamidullaeva, L., \& Vasin, S. (January 01, 2019). Web-Based Learning and Development of University's Electronic Informational Educational Environment. International Journal of Web-Based Learning and Teaching Technologies, 14, 1, 32-53..

Parks, M. (2009). What will we study when the Internet disappears? Journal of ComputerMediated Communication, 14(3), 724-729.

Shankar, P. R., Piryani, R. M., Singh, K. K., \& Karki, B. M. S. (December 13, 2012). Student feedback about the use of role plays in Sparshanam, a medical humanities module. F1000research.

Starodubceva E.A. (2017) Primeneniya Internet resursov pri obuchenii inostrannomu (anglijskomu) yazyku // Elektronnoe nauchnoe izdanie «Trudy MEHLI» / URL: https://refdb.ru/look/2305701.html

Ter-Minasova S.G. (2000) YAzyk i mezhkul'turnaya kommunikaciya / S.G. Ter-Minasova. M.: Izd-vo Moskva. P. 261 